\title{
Analysis to the Potential of Rainwater Resources Utilization in Kunming area
}

\author{
ZOU Yu-ling, a , MA Jian-wu, b * \\ ${ }^{1}$ Gold Mantis School of Architecture, Soochow University, Soochow, Jiangsu, China \\ a824195992@qq.com, bmajianwu@suda.edu.cn
}

Keywords: Kunming; precipitation; evaporation; potential of rainwater resources utilization

\begin{abstract}
Water shortage is very serious in kunming area. Based on the precipitation and evaporation data of 2001-2011 of Kunming provided by Yunnan Meteorological Bureau, the article analyzes the change features of annual, seasonal and monthly rainfall and evaporation over the last 11 years. What's more, by referring to the calculation method of utilization potential of rainwater resources, it estimates the amount of rainwater resources utilization in Kunming area. The results show that the average annual evaporation in Kunming area is higher than that of average annual rainfall, so there are almost no rainwater resources available. But the average rainfall is more than the average evaporation in some months; this part of rainwater resource has the utilization potential. Usually the calculation methods for rainwater resources will take rainfall, evaporation, runoff, infiltration and landscape water replenishment and other factors into account on basis of water balance. This paper can also find the existing problems based on the data comparison of rainfall and evaporation in Kunming, and estimate the utilization potential of rainwater resource. It has great significance for using the urban rainwater to alleviate pressure on urban water consumption. What's more, this analysis aims to provide reference for rainwater management strategy and the design of park green space in Kunming area.
\end{abstract}

\section{Introduction}

With the acceleration of urbanization, the problem of urban water shortage is increasingly serious, while lots of greenbelt competes for water with human. The rainwater is the most fundamental, direct and economical water resource, an important part of water circulation system in natural world. It plays a key role in regulating, supplementing regional water resources and improving and protecting the ecological environment [1]. It has great significance for using the urban rainwater to alleviate pressure on urban water consumption, so it is particularly important to utilize rainwater resources efficiently. By analyzing the distribution features of rainfall amount and evaporation capacity in Kunming area and calculating the utilization amount of rainwater resource, we hope to take advantage of urban rainwater effectively, which has an important meaning in alleviating the water shortage problem [2].

\section{The Introduction of the Study area and the Selection of Analysis Data}

The Introduction of the Study area. The administrative division of Kunming includes six districts: Panlong District, Wuhua District, Xishan District, Guandu District, Dongchuan District, Chenggong District, and seven counties: Jinning County, Fumin County, Songming County, Xundian Hui and Yi Nationality Autonomous County, Yiliang County, Shilin Yi Nationality Autonomous County (formerly Lunan County), Luquan Yi and Miao Nationality Autonomous County and one more Anning City. Kunming is located in central Yunnan-Guizhou Plateau in southwest China, east longitude $102^{\circ} 10^{\prime} \sim 103^{\circ} 40^{\prime}$, northern latitude $24^{\circ} 23^{\prime} \sim 26^{\circ} 22^{\prime}$, south to Dianchi Lake, and three sides of Kunming is surrounded by mountains [3]. Kunming belongs to subtropical humid monsoon climate with annual average temperature of $15.5{ }^{\circ} \mathrm{C}$. It is the political, economic, cultural, science and technology, transportation center of Yunnan Province, and it's also a tourism city, commerce city in 
western region. Calculating 2.95 million populations in Kunming by 2006, per capita water resources amount is only 278 square meters, which is less than 11 percent of the national per capita. On one hand, the available amount of water resources is limited, which causes supply and demand contradiction; on the other hand, the destruction of the water environment and the serious waste of water resources influence each other, leading to the water shortages in this region[4].

Materials. The date of the rainfall amount and evaporation capacity cited here is mainly meteorological data provided by Yunnan Provincial Meteorological Bureau from 2001 to 2011 and five meteorological stations (Kunming, Fumin, Songming, Anning and Dongchuan) are selected as representative analysis. By comparing and calculating, we collate and conclude rainfall and evaporation rules from 2001 to 2011 as well as the utilization potential of rainwater resource, which provide the basis for the necessity of Kunming rainwater resource utilization.

Methods. The Rainfall Patterns in Kunming area.

Basic Information of rainfall in Kunming area. We can see that the annual average rainfall amount in Kunming area is between $681.5 \mathrm{~mm}-981.8 \mathrm{~mm}$, average of $844.6 \mathrm{~mm}$ from 2001 to 2011 annual rainfall data of Kunming.

The quarter average rainfall distribution of Kunming area is substantially the same. In the first quarter, the rainfall is $35.6 \mathrm{~mm}-42 \mathrm{~mm}$; the second quarter, $165.8 \mathrm{~mm}-348.9 \mathrm{~mm}$; the third quarter, $274.2 \mathrm{~mm}-488 \mathrm{~mm}$; the fourth quarter, $89.8 \mathrm{~mm}-110.8 \mathrm{~mm}$. This shows that the lowest rainfall is in the first quarter, which only takes up 4.5 percent of the annual average rainfall; the maximum rainfall is in the third quarter, which takes up about $48.9 \%$ of the annual average rainfall and it's much higher than the other three quarters. The distribution of the rainfall in four quarters is uneven, and the rainfall in the second and third quarter is about five times of the first and fourth quarter.

Since Kunming area is affected by geographical location, atmospheric circulation and other factors, it has obvious rainy and dry season. Dry season is from November to April of the next year, under the control of southwest dry warm air mass, it has sunny weather, little cloud cover, abundant sunshine, little rainfall and low humidity. Rainy season is from May to October, with the northward and arrival of the Pacific subtropical, the southwest warm wet air will enter Kunming and bring a lot of precipitation, the city starts entering the rainy season [5-6].

From the monthly average rainfall distribution of 2001-2011 in Kunming area,the average rainfall of each site presents quite uneven characteristics of monthly distribution (Table 1), rainfall process mainly appears from May to October, accounting for $86.8 \%$ to $88.4 \%$ of average annual rainfall, while the rainfall from November to April of next year is relatively low, only accounting for $12.3 \%$ to $15.2 \%$ of the total average annual rainfall.

Table 1. 2001 to 2011 month average rainfall in Kunming area [mm].

\begin{tabular}{ccccccccccccc}
\hline & Jan. & Feb. & Mar. & Apr. & May. & Jun. & Jul. & Aug. & Sep. & Oct. & Nov. & Dec. \\
\hline Kunming & 15.1 & 9.0 & 14.0 & 28.7 & 83.6 & 160.7 & 201.3 & 184.1 & 102.6 & 69.0 & 27.7 & 14.1 \\
Fumin & 11.5 & 9.4 & 14.8 & 31.0 & 85.5 & 170.3 & 160.7 & 127.4 & 77.7 & 63.0 & 26.1 & 11.4 \\
Songming & 15.0 & 9.7 & 17.3 & 29.5 & 97.8 & 221.6 & 197.9 & 178.4 & 103.8 & 68.5 & 28.7 & 13.6 \\
Anning & 14.6 & 8.3 & 12.6 & 31.9 & 77.7 & 156.2 & 201.2 & 163.0 & 93.1 & 63.5 & 26.7 & 12.0 \\
Dongchuan & 13.4 & 10.8 & 14.2 & 25.8 & 85.6 & 167.5 & 111.4 & 91.3 & 71.6 & 64.7 & 18.5 & 6.6 \\
Average & $\mathbf{1 3 . 9}$ & $\mathbf{9 . 4}$ & $\mathbf{1 4 . 6}$ & $\mathbf{2 9 . 4}$ & $\mathbf{8 6 . 0}$ & $\mathbf{1 7 5 . 3}$ & $\mathbf{1 7 4 . 5}$ & $\mathbf{1 4 8 . 8}$ & $\mathbf{8 9 . 8}$ & $\mathbf{6 5 . 8}$ & $\mathbf{2 5 . 5}$ & $\mathbf{1 1 . 5}$ \\
\hline
\end{tabular}

Analysis of Rainfall Patterns. The total average annual rainfall in Kunming area is $844.6 \mathrm{~mm}$. According to the classification criteria [7] for wet and dry areas, Kunming obviously belongs to humid zone, but the rainfall distribution during the year is extremely uneven, quarterly differences is obvious and the wet and dry seasons are distinct.

As for the rainfall in the four quartes, the minimal rainfall is in the first quarter, with average rainfall between 35.6 and $42 \mathrm{~mm}$, accounting for only about 4.5 percent of average annual rainfall; the maximum rainfall is in the third quarter, between $274.2 \mathrm{~mm}-488 \mathrm{~mm}$, accounting for about $48.9 \%$ of the annual rainfall, and it's much higher than the other three quarters. The distribution of the rainfall 
in four quarters is uneven, and the rainfall in the second and third quarters is about five times of the first and fourth quarter.

From the month pattern, the rainfall distribution of Kunming during the year is extremely uneven. Rainfall varies greatly from dry season to wet season, rainfall process mainly appears from May to October, accounting for $87.6 \%$ of total annual rainfall, while rainfall from November to April of the next year is relatively low, only accounting for $12.4 \%$ of the whole year.

\section{The Evaporation Patterns in Kunming}

Basic Condition of Kunming Evaporation Capacity. The average annual evaporation in Kunming is $1216.3 \mathrm{~mm}-2459.3 \mathrm{~mm}$ with average evaporation $1824.5 \mathrm{~mm}$.

The average evaporation of the first quarter in Kunming is $324.2 \mathrm{~mm}-695.7 \mathrm{~mm}$; the second quarter is $375.7 \mathrm{~mm}-799.3 \mathrm{~mm}$; the third quarter is $287.5 \mathrm{~mm}-553.2 \mathrm{~mm}$; and the fourth quarter $229 \mathrm{~mm}-411 \mathrm{~mm}$. The average evaporation from the first quarter to the fourth quarter respectively accounts for approximately $28.1 \%, 32.9 \%, 22 \%, 17 \%$ of the annual evaporation amount; the fourth quarter is the minimum while the maximum is in the second quarter. Quarterly difference of average evaporation in Kunming is still obvious.

From the average monthly evaporation distribution of Kunming in Table 2, the evaporation process in Kunming mainly concentrates from March to May, usually accounting for about $36.8 \%$ of the annual average evaporation amount while April reaches the maximum; the months of smaller evaporation appear from October to December while the smallest is in December, the total evaporation amount of the three months generally occupy only about $17 \%$ of the annual average evaporation amount.

Table 2. Monthly average evaporation of 2001-2011 in Kunming area[mm].

\begin{tabular}{ccccccccccccc}
\hline & Jan. & Feb. & Mar. & Apr. & May. & Jun. & Jul. & Aug. & Sep. & Oct. & Nov. & Dec. \\
\hline Kunming & 81.8 & 105.9 & 136.5 & 148.4 & 127.1 & 100.2 & 96.1 & 100.4 & 91.0 & 75.8 & 79.4 & 73.7 \\
Fumin & 129.6 & 167.0 & 219.9 & 247.4 & 201.2 & 155.3 & 143.9 & 138.6 & 117.5 & 115.9 & 105.3 & 103.2 \\
Songming & 129.7 & 169.9 & 225.4 & 251.1 & 201.3 & 139.9 & 129.9 & 127.6 & 104.7 & 93.4 & 96.3 & 97.9 \\
Anning & 122.2 & 166.1 & 218.6 & 253.6 & 209.4 & 160.8 & 143.9 & 140.7 & 117.6 & 106.4 & 99.9 & 95.8 \\
Dongchuan & 160.8 & 235.2 & 299.7 & 326.4 & 286.7 & 186.2 & 194.6 & 183.5 & 175.1 & 136.3 & 136.7 & 138.0 \\
Average & $\mathbf{1 2 4 . 8}$ & $\mathbf{1 6 8 . 8}$ & $\mathbf{2 2 0 . 0}$ & $\mathbf{2 4 5 . 4}$ & $\mathbf{2 0 5 . 1}$ & $\mathbf{1 4 8 . 5}$ & $\mathbf{1 4 1 . 7}$ & $\mathbf{1 3 8 . 2}$ & $\mathbf{1 2 1 . 2}$ & $\mathbf{1 0 5 . 6}$ & $\mathbf{1 0 3 . 5}$ & $\mathbf{1 0 1 . 7}$ \\
\hline
\end{tabular}

Analysis of Evaporation. Total average annual evaporation in Kunming is $1824.5 \mathrm{~mm}$. The evaporation distribution of the region during the year is very uneven and it has significant quarterly difference. The evaporation is large in low rainfall month, which causes Kunming's drought condition.

From view of every quarter, the minimum evaporation is the first quarter with average evaporation between $229 \mathrm{~mm}-411 \mathrm{~mm}$, accounting for about $17 \%$ of the annual average evaporation; the evaporation of the second quarter is the largest between $375.7 \mathrm{~mm}-799.3 \mathrm{~mm}$, accounting for about $32.9 \%$ of total annual rainfall. We can see the distribution differences of evaporation for four quarters are not as obvious as the rainfall.

From the view of monthly pattern, the evaporation distribution in Kunming during the year is quite uneven, which mainly concentrates from March to May, accounting for $36.8 \%$ of the annual rainfall, while the evaporation from October to December is relatively lower, accounting for $17 \%$ of the whole year.

\section{The Utilization Potential of Rainwater Resource in Kunming area}

The Concept of Utilization Potential of Rainwater Resource. The Utilization potential analysis of urban rainwater is the prerequisite of utilizing urban rainwater. Only through analyzing the rainwater utilization potential, we can know whether the urban rainwater resource is abundant or not and its 
distribution during the year, which helps to provide the basis for arranging urban rainwater utilization measures. The urban rainwater utilization potential refers to the amount of rainfall resource could be developed to utilize under certain technical and economic conditions in a particular region and a certain period of time, this amount is between the total amount of urban rainwater and the utilization amount of urban rainwater. The water amount after urban rainwater deducts the evaporation loss and else is the utilization potential of urban rainwater resource [8].

The Calculation of Rainwater Resource Utilization. Calculation and analysis methods for the utilization potential of urban rainwater resource usually have four kinds [9]: The first is comprehensive runoff coefficient method, which uses comprehensive runoff coefficient to calculate regional rainfall utilization and practical potential; the second uses experience formula method to estimate the available amount of urban rainwater; the third comprehensively analyzes each aspect of rainfall runoff processes to calculate the utilization potential of rainwater resource based on the method of water balance. The fourth is based on different land surface patterns to analyze the utilization potential of urban rainwater. Four methods have their own characteristics and application scope, in accordance with existing data and the concept of utilization potential of rainwater resource, in this particular area Kunming, estimation method is simply employed, namely the water amount after rainwater deducts the evaporation is the utilization potential of rainwater resource. If the resulting value is positive, indicating the amount of rainwater resource utilization exists, on the contrary, it is the amount of rainfall loss.

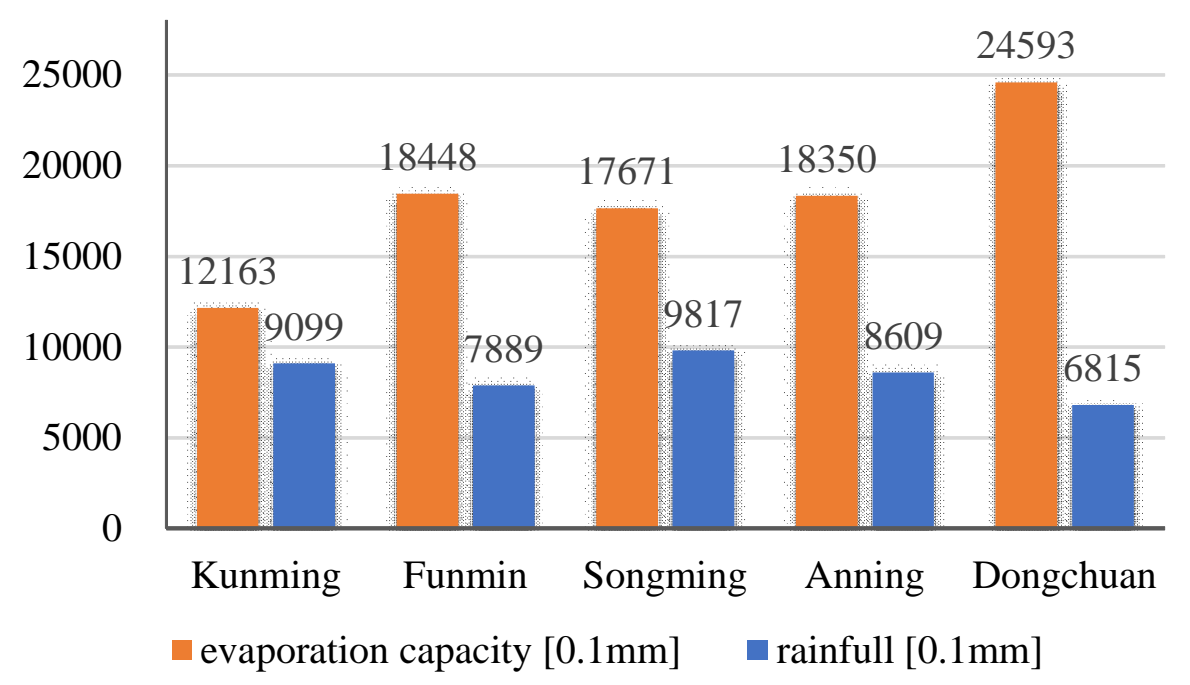

Fig. 1 Comparison of average annual evaporation and rainfall distribution in Kunming area.

As can be seen from Fig.1, the 12-month average annual evaporation is greater than the average annual rainfall in Kunming, although the average annual rainfall is up to the national division of humid areas, Kunming still belong to a very dry area because the factor yearly evaporation is much greater than the rainfall.

Table 3 presents the difference value after 12-month average rainfall minus evaporation in Kunming, the annual average difference values of the five weather stations are all negative, the total average annual evaporation is greater than the average annual rainfall, but it can't rule out the average annual rainfall of some months is greater than the amount of evaporation. The rainfall from June to September in Kunming is more than the evaporation, the average annual amount of rainwater resource utilization is $261 \mathrm{~mm}$, while water deficit is $572.4 \mathrm{~mm}$; the rainfall of June and July is more than evaporation with rainwater resource utilization amount $31.8 \mathrm{~mm}$ while the water deficit is $1087.8 \mathrm{~mm}$; the rainfall from June and September in Songming is more than evaporation with rainwater resource utilization amount $200.5 \mathrm{~mm}$ while the water deficit is $985.8 \mathrm{~mm}$; the rainfall of July and August in Anning is more than evaporation with rainwater resource utilization amount $79.6 \mathrm{~mm}$ while the water 
deficit is $1053.7 \mathrm{~mm}$; the monthly average evaporation in Dongchuan is more than the monthly average rainfall.

Based on the analysis of 12-month observation data, it shows that the average annual total evaporation is much greater than the rainfall amount in Kunming. According to the difference value comparison between the rainfall amount and evaporation amount, Kunming from February to April suffers from serious water shortages; the rainfall amount from June to August is greater than the evaporation amount. From the view of the total amount, the utilization amount of rainfall resources is $573 \mathrm{~mm}$, there is loss amount of $5472.6 \mathrm{~mm}$ requiring supplement each year. From the view of average value, the utilization amount of rainwater resource is $70.3 \mathrm{~mm}$ with annual average loss amount of $1050.2 \mathrm{~mm}$. This indicates that Kunming on the whole is an area of drought and water shortage, but because of the uneven rainfall distribution, the differences of quarterly, monthly rainwater resource utilization potential are quite large. A reasonable assessment against the potential and benefits of rainwater resource utilization should be based on the principle of water balance and the rainfall, evaporation, runoff, infiltration and landscape water replenishment and other factors should also be considered [10].

Table 3. The statistics for annual average rainwater resource utilization amount in Kunming area [mm] (Rainfall minus Evaporation).

\begin{tabular}{|c|c|c|c|c|c|c|c|c|c|c|c|c|c|}
\hline & Jan. & Feb. & Mar. & Apr. & May. & Jun. & Jul. & Aug. & Sep. & Oct. & Nov. & Dec. & $\begin{array}{c}\text { Annual } \\
\text { Averag } \\
\mathrm{e}\end{array}$ \\
\hline Kunming & -66.7 & -96.9 & -122.5 & -119.7 & -43.5 & 60.5 & 105.2 & 83.7 & 11.6 & -6.8 & -51.7 & -59.6 & -306.4 \\
\hline Fumin & -118.1 & -157.6 & -205.1 & -216.4 & -115.7 & 15 & 16.8 & -11.2 & -39.8 & -52.9 & -79.2 & -91.8 & $\begin{array}{c}-1055 \\
9\end{array}$ \\
\hline $\begin{array}{l}\text { Songmin } \\
\mathrm{g}\end{array}$ & -114.7 & -160.2 & -208.1 & -221.6 & -103.5 & 81.7 & 68 & 50.8 & -0.9 & -24.9 & -67.6 & -84.3 & -785.4 \\
\hline Anning & -107.6 & -157.8 & -206 & -221.7 & -131.7 & -4.6 & 57.3 & 22.3 & -24.5 & -42.9 & -73.2 & -83.8 & -794.1 \\
\hline $\begin{array}{l}\text { Dongchu } \\
\text { an }\end{array}$ & -147.4 & -224.4 & -285.5 & -300.6 & -201.1 & -18.7 & -83.2 & -92.2 & -103.5 & -71.6 & -118.2 & -131.4 & $\begin{array}{c}-1777 \\
8\end{array}$ \\
\hline Average & -110.9 & -159.4 & -205.4 & -216 & -119.1 & 26.8 & 32.8 & 10.7 & -31.4 & -39.8 & -78 & -90.2 & -979.9 \\
\hline
\end{tabular}

\section{Discussion and Conclusion}

Through the rough estimation of the utilization amount of rainwater resource from 2001 to 2011 in Kunming, we know that although the average annual utilization amount of rainwater resources is negative, the evaporation is greater than the rainfall in June, July and August. And also the average annual rainwater resource utilization reaches $70.3 \mathrm{~mm}$ while the average annual rainfall deficit is $1050.2 \mathrm{~mm}$.

In certain months, the rainfall amount is less than the evaporation amount, and this rainwater hasn' $t$ been used but go to waste or infiltrate into the soil. Suppose that all rainfall in Kunming infiltrates into the soil, the rainwater will be evaporated and there is a loss in the whole process of evaporation; if runoff appears, a part of the rainwater will flow away in infiltration, the loss amount is even greater to cause arid soil, which also shows that the drought condition in Kunming is very serious.

Through the analysis, the reasons for arid Kunming are the following aspects: First, due to the local strong sunshine, especially in the dry season, the evaporation is relatively strong; the second is the uneven annual rainfall, obvious wet and dry seasons; the third is in the rainy season, the urban rainwater will produce a large runoff and effective measures to collect rainwater are not performed.

For the fact that Kunming is facing water shortage problem, the rainwater resource utilization should be placed in a strategic height. The public awareness of water conservation should be raised. And also we need to use technical measures of rainwater management to manage the rainwater purposefully and pointedly. By collecting the available part of rainwater resources to make up the water shortage in some months, thus the shortage of urban water resources can be alleviated. Using the park green space to manage rainwater is the most economical and ecological way because the park green space is a natural filter and storage of rainwater. However, the rainwater in present park green 
space hasn't been managed effectively, and it even causes urban inland inundation. What's worse, in dry season, most greenbelt struggles for water with people, which intensifies the shortage of rainwater resources. Therefore, after analyzing the utilization characteristics of rainwater resources in Kunming, it is very necessary to take corresponding and effective rainwater management strategies for rainwater collection and treatment so as to alleviate the issue of urban water resources shortage and the contradiction between water supply and demand.

Usually the calculation methods for rainwater resources will take rainfall, evaporation, runoff, infiltration and landscape water replenishment and other factors into account on basis of water balance. This paper can also find the existing problems based on the data comparison of rainfall and evaporation in Kunming, and estimate the utilization potential of rainwater resource.

\section{Acknowledgement}

This paper is supported by the National Natural Science Foundation of China: Multi objective management strategy of rain water in the park green space of Yunnan subtropical high altitude monsoon climate zone, 51168043.

\section{References}

[1] C. L. You, Utilization Feasibility Research of Urban Rainwater, D. Xi'an University of Architecture and Technology, 2006.

[2] L. M. Zhang, Z. Y. Wei, Z. P. Xi, The Study on the Distribution Characteristics of rainfall amount and Evaporation Capacity in Different Areas in Hainan Province over 30 Years, J. Chin. Agr. Sci. Bull. 22(4) (2006) 403-407.

[3] China City Statistical Yearbook, M. Beijing: New World Press, 1986.

[4] S. D. Fang, Y. Huang, S. G. Bo, The Analysis of Water Resource Evolution in Kunming City Development Process, J. Water Res. Prot. 26(6) (2010) 32-36.

[5] L. M. Hua, S. Q. Yang, The Analysis on the Characteristics and Variation Tendency of Precipitation in the Main City Of Kunming, J. People Pearl River, (3) (2010) 6-8.

[6] The Pandect of Yunnan meteorological disasters, M. Beijing: China Meteorological Press, 2000.

[7] X. S. Lin, D. C. Chen, Q. R. Qin, M. Z. Liu, Concise geographic Manual, M. Nanning: Guangxi People's Publishing House, 1984.

[8] X. F. Huang, S. D. Guo, X. H. Wei, The Analysis Model Urban Rainwater Utilization Potential Based on the Water Balance, J. Wuhan U. (Eng. Sci.), 40(2) (2007) 17-33.

[9] W. D. Chen, The Analysis on the Utilization Potential and Feasibility of Wuhan City Rainwater Resource, D. Central China Normal University, 2014.

[10]X. Chen, The Necessity and Potential Analysis of Maoming City Rainwater Utilization, J. Huizhou U. J. (Nat. Sci.), 29(3) (2009) 81-84. 